\title{
De heróis e anti-heróis: escolhas estilísticas e construções de significado na narcotelenovela colombiana Escobar, el patrón del mal,
}

\author{
Simone Maria Rocha ${ }^{1}$
}

\begin{abstract}
Resumo: Proponho neste trabalho demonstrar e compreender a importância de escolhas estilísticas em dimensões específicas da narcotelenovela Escobar, el patrón del mal (TV Caracol, 2012): na figuração de heroísmo e vilania nos personagens de Luis Carlos Galán e Pablo Escobar, respectivamente. A partir desse recorte salientarei elementos formais que cumprem papel na construção dos significados objetivados pelos realizadores e, assim, ressaltarei como o estilo opera e conforma aspectos textuais e contextuais.
\end{abstract}

Palavras-chave: estilo televisivo; narcotelenovela; Colômbia, Pablo Escobar.

\begin{abstract}
In this paper I propose to expose and understand the relevance of stylistic choices in specific dimensions of the narcotelenovela Escobar, el patrón del mal (TV Caracol, 2012): in the figuration of heroism and villainy in the characters of Luis Carlos Galán and Pablo Escobar respectively. From this I will stress formal elements which play a role in the construction of objectified meanings by the authors, in order to stress how the style operates and conforms textual and contextual aspects.
\end{abstract}

Keywords: television style, narcotelenovela, Colombia, Pablo Escobar.

\section{Introdução}

A televisão é um meio com linguagem audiovisual e formas estilísticas próprias. O modo como ela conjuga elementos técnicos, tais como iluminação, cenário, trilha sonora e enquadramentos, redunda em estilos característicos que contribuem na identificação do tipo de narrativa que o meio tende a privilegiar. Sendo assim, tanto os aspectos materiais quanto imateriais que constituem o dispositivo televisivo jogam papel importante no modo como a TV configura seus regimes de representação.

${ }^{1}$ Professora Associada do PPGCOM/UFMG, onde realizou seu estágio pós-doutoral. Doutora em Comunicação e Cultura pela UFRJ. Líder do Grupo de Pesquisa em Comunicação e Cultura em Televisualidades (COMCULT/PPGCOM/UFMG). E-mail: rochasimonemaria@gmail.com. 
A partir de uma análise que tem como fio condutor a abordagem metodológica do estilo televisivo, conforme apresentada por Jeremy Butler (2010), e de modo a evidenciar os elementos estilísticos escolhidos na narrativa, o objetivo deste trabalho é o de demonstrar e compreender como se deu a figuração de heróis e anti-herói na produção colombiana Escobar, el patrón del mal, produzida e exibida pela TV Caracol, 2012. Argumentamos pela relevância de tal análise tendo em vista duas razões.

A primeira está relacionada à importância da televisão no contexto colombiano como explica o historiador e analista de meios Fabio López de la Roche (2014). Segundo ele, um ponto central destas narrativas televisivas (ao menos no que diz respeito ao seu funcionamento dentro do contexto colombiano) é que, para as audiências massivas, ou seja, a maioria dos colombianos que não leem jornais impressos diários nem livros de história, nem pertencem ao mundo da cultura letrada, tais produtos constituem-se na única possibilidade de conhecimento da história recente do país. Essas construções narrativas ficcionais, nas quais a montagem televisiva superpõe materiais documentais com materiais ficcionais, devem merecer uma crítica sistemática por parte de historiadores e outros cientistas sociais. Tal fato nos aponta para um aspecto relevante das escolhas narrativas e estilísticas adotadas. Como a série explora a historia do narcotraficante Pablo Escobar Gaviria, que participou no assassinato de vários dirigentes políticos colombianos, na década de 1980, houve uma preocupação, por parte dos realizadores, em contar uma história que de algum modo evidenciasse a atuação firme e combativa desses dirigentes, que demonstrasse que, apesar de todo o horror espalhado por Colômbia naqueles anos, houve quem lutasse contra esse império do mal, a ponto de darem suas vidas como verdadeiros heróis por uma causa comum.

A segunda razão diz respeito ao crescente número de produções televisuais envolvendo o tema do narcotráfico, seu desdobramento, influência e inserção na estrutura econômica e social das sociedades nas quais está presente (ORDOÑEZ, 2012). Muitas dessas narrativas nos sugerem compreender que a mercantilização da violência é o resultado direto de um governo frágil e do avanço da "lógica de mercado", numa situação segundo a qual a existência 
humana e os direitos humanos dependem da posição que se ocupa na hierarquia econômica, relegando parte da população, como os camponeses e colonos expulsos de suas terras (desplazados), os pobres, os migrantes, os dependentes de droga, os trabalhadores braçais, as prostitutas etc, à condição de "descartáveis". É nesse sentido que muitas dessas produções convertem-se em relatos, por vezes genuínos e instrutivos, sobre a violenta modernização econômica e social que converteu a sociedade colombiana de uma indústria caseira a centro mundial da produção e comércio ilegal de cocaína.

Neste cenário, surge o que alguns autores denominaram narcocultura (RINCÓN, 2009) como sendo uma forma de auto-representação assumida pelos narcos, que inclui uma estética ostentatória, um consumismo notório e a busca por status social. Para Omar Rincón (2013, 2009), não é necessário ser um traficante de drogas para compartilhar seus valores e sua mentalidade. A cultura das drogas, ou narcocultura, espalhou sua simbologia e seus modos de ser pelas sociedades latino-americanas. Se as formas de ascensão social por meio da educação, do trabalho ou da participação política são excludentes e injustas, a narcocultura aparece com uma importância significativa, pois ela pode representar a entrada do povo, mesmo que de maneira desviada, na modernidade.

Escobar, el patrón del mal, contempla vários desses aspectos e tem gerado grande debate e controvérsia em torno de seus significados pretendidos. Para alguns, ela pode ser considerada uma narrativa espetacular e apologética do crime e a uma imagem negativa da Colômbia. Sendo assim, o melhor seria esquecer ou ignorar o passado. Já outras posições defendem que o passado precisa ser "passado a limpo", ser revisto, criticado, e conhecido para que não se repita no presente.

Diante das várias possibilidades apresentadas, o extrato que escolhemos para esta análise corresponde às sequências dos discursos políticos de Luis Carlos Galán, pré-candidato à presidência, e de Pablo Escobar, que se apresentou como suplente do candidato Ravier Ortiz. Nesse momento da narrativa, Galán e Escobar ainda eram parceiros no novo liberalismo, até que o 
Galán descobre que Escobar é traficante de drogas e decide expulsá-lo do partido. Pablo, por sua vez, sem saber de nada, ainda mantém o apoio à candidatura de Galán.

\title{
Escobar, el patrón del mal
}

Miguel Cabañas, professor de estudos latino Americanos e Chicanos da Universidade de Michigan, aponta que a primeira narrativa a tratar do tráfico de drogas e sua influência na sociedade foi Sin tetas no hay paraíso (TV Caracol, 2006). Mas, é possível recuar no tempo e considerar La viuda de la máfia (RCN, 2004) como ponto de partida. Desde então, várias outras produções foram lançadas com destaque para El cartel de los sapos (TV Caracol, 2008), El Capo (RCN, 2008 e 2012), Las muñecas de la máfia (TV Caracol, 2009), Rosaro Tijeras (RCN, 2010), Escobar, el patrón del mal (TV Caracol, 2012), e Tres Caínes (RCN, 2013), sobre os irmãos Fidel, Vicente e Carlos Castaño, organizadores de grupos paramilitares na Colômbia, conformados para lutar contra os grupos guerrilheiros. São produções que apresentam

\begin{abstract}
Histórias que justificam, argumentam e absolvem as formas de como se chega a ser traficante ou mulher de silicone, ou assassino violento; epopeias melodramáticas e cômicas (o humor não pode faltar no popular!) que celebram os métodos paralegais de ascensão social: narrativa que celebra o triunfo rápido expressado pelo dinheiro, armas, bebida, mulheres, sexo. Este novo e surpreendente estilo, tom e textura da novela colombiana reconhece explicitamente que somos a cultura do narcotráfico em estéticas, valores e referências. Somos uma nação que assumiu sua marca do tráfico de que vale tudo para sair da pobreza: peitos, uma arma, ser político corrupto, traficar cocaína, ser guerrilheiro, ser paraco (paramilitar) ou estar no governo (RINCÓN, 2013, p. 210).
\end{abstract}

Para Luiz Felipe Neira Reyes, sempre que surge uma nova produção em torno do tema "[...] ha emergido una discusión en la sociedad que interroga e interpela estas ficciones con diversos puntos de vista en la que se enfocan sus dimensiones éticas, estéticas, poéticas, políticas, históricas, sociales o culturales" (REYES, 2014, p. 2).

Escobar, el patrón del mal foi produzia pela TV Caracol, da Colômbia, e vem sendo apreciada em toda a América Latina. Países como Cuba e Argentina engajaram-se na assistência da ficção seriada com significativos índices de audiência. Em Cuba, onde o consumo pirata de cinema e de séries de televisão 
está muito difundido, a narrativa tem circulado intensamente entre os moradores de Havana e de outras cidades do país². No Brasil, foi exibida a versão compacta internacional, que estreou em 15 de setembro de 2014, composta de 74 episódios extraídos do original colombiano de 113 capítulos ${ }^{3}$. Foi transmitida pelo canal +Globosat, de segunda a sexta-feira, às 4h, 9h, 14h e $21 \mathrm{~h}$ - as três primeiras exibições reprisavam o episódio inédito, que era transmitido às 21h. Cada episódio teve a duração de 45 minutos 4 .

Escobar, el patrón del mal, tem se revelado um fenômeno de crítica e de audiência desde seu país de origem, onde alcançou dez milhões de telespectadores. Para Neira Reyes e López de la Roche (2014, p. 2 ):

Escobar, el patrón del mal, producida por la televisión privada y con la dirección de Carlos Moreno, es una serie dramatizada que repite una fantasía, cercana de algún modo a las "subculturas del narcotráfico", estudiada por el periodista Alonso Salazar y la socióloga Ana Jaramillo, el modo de vida de la delincuencia organizada del Valle de Aburrá: la emergencia de traquetos (narcotraficantes) y pistolocos (sicarios) que se construyen con elementos del consumismo moderno, de la tradición de la delincuencia y con elementos de la cultura paisa: el mito de la superioridad de la raza antioqueña, la religiosidad popular, el culto a la madre, el paternalismo y la hombría y también, el parlache y el humor popular. Y en esta "subcultura", junto a su poder económico y político aparecen unas violencias que se tramitan a nivel local, nacional e internacional.

Considerada como uma série biográfica cujo final já é sabido, é notório que o eixo dramático recaiu sobre o modus vivendi de Escobar, sua personalidade arrogante, seu estilo de vida extravagante e a construção de sua trajetória criminosa até tornar-se o maior narcotraficante de cocaína do mundo.

É por isso que a série mostra Pablo Escobar passar de um garoto astuto a um jovem ambicioso e sem escrúpulos que jura tirar a própria vida se não

\footnotetext{
${ }^{2}$ López de la Roche revelou que, durante sua ida a Cuba, em julho de 2013, pode perceber através de seus contatos com dezenas de cubanos, a maioria se referiu a Escobar, el patrón del mal, como uma série preferida ou da qual havia gostado muito.

3 Disponível em: <http://oglobo.globo.com/cultura/revista-da-tv/pablo-escobarsenhor-do-trafico-estreia-mostrando-todos-os-lados-do-narcotraficante13922019\#ixzz3HrVLs8CI>. Acesso em: 01 nov. 2014.

4 Disponível em: <http://veja.abril.com.br/blog/temporadas/trailers/pablo-escobar-elpatron-del-mal-estreia-no-brasil-em-setembro/>. Acesso em: o1 nov. 2014.
} 
conseguir um milhão de pesos aos 25 anos, e iniciar uma vertiginosa carreira no mundo do crime, que começa com o roubo de lápides e carros e termina com o domínio do mundo do contrabando. Mais ainda, Escobar, depois de conhecer o nascente negócio do tráfico de drogas, decide converter-se no maior exportador de cocaína para Estados Unidos e Europa. Em sua escalada, acompanhamos Escobar burlar fronteiras, criar rotas, construir o Cartel de Medellín, entrar para a política formal e, ao ser expulso pelos demais representantes do poder constituído, empreender uma guerra frontal contra o Estado, colocando sob a mira de seu poder criminoso todos aqueles que se opuseram a ele. Esta expulsão da política formal faz com que a narrativa seriada introduza o tema do magnicídio e do narcoterrorismo como resposta do crime organizado frente à ação do Estado colombiano.

O Capo mandou assassinar juízes, policiais, políticos, jornalistas e todos que ameaçavam o seu poder. Passou a viver escondido e isolado até sua captura, levada a cabo por um comando especializado e dedicado a procurá-lo, com táticas que envolveu a perseguição à sua família, de modo a que ele perdesse o controle da situação e se tornasse vulnerável a ponto de ser localizado e morto em dois de dezembro de 1993.

Em Escobar, el patrón del mal temos a figuração do profundo dano que a máfia antioquenha causou na estrutura social e institucional colombiana, incluindo organismos governamentais, de segurança pública, partidos políticos bem como os prejuízos que tal ação acarretou no funcionamento da democracia, dado o alto grau de corrupção que se instaurou naquele país. Por fim, vislumbramos o papel econômico do narcotráfico a ponto de tornar-se o combustível que nutriu o conflito armado entre guerrilhas, organizações paramilitares e exército nacional.

De fato, esta produção chegou a níveis relativamente profundos da problemática na medida em que evidenciou a presença do narcotráfico nas estruturas político-sociais da Colômbia, coisa que raramente vemos no Brasil. 
Sin embargo, a diferencia de lo que ocurre con otras grandes series televisivas, como las norte-americanas The Wire o 24, ésta se sigue con incomodidad, un difuso malestar provocado por la sensación de que, a diferencia de lo que aquéllas relatan, Escobar, el patrón del mal no es ficción sino la descripción más o menos fidedigna de una pesadilla que padeció Colombia durante unos años que vivió no bajo el imperio de la ley sino del narcotráfico. 5

Isso não quer dizer que escolhas não tenham sido feitas. Alguns focos narrativos foram privilegiados. O primeiro foi o que se concentrou na figura polêmica e controversa de Escobar, apelidado de Robin Hood de Medellín, assassino cruel de centenas de opositores, pai dedicado, terrorista, excêntrico colecionador de animais exóticos, político populista e magnata do tráfico de cocaína, que praticamente monopolizou as vendas globais desta droga durante uma década. O segundo abordou o funcionamento do sistema político da Colômbia, apresentado como poroso à corrupção e ao poder econômico de Escobar, que se mostrou bastante eficaz ao garantir a impunidade aos traficantes. Vimos várias ações de suborno a agentes institucionais para que o processo de produção da cocaína não sofresse nenhum impedimento.

$\mathrm{O}$ ponto que queremos ressaltar em nossa análise diz respeito a um terceiro enfoque que procurou mostrar as tentativas do governo em combater esse mal que assolou as instituições e instalou a corrupção entre os agentes oficiais e públicos da política formal. Em muitos capítulos, o telespectador acompanha operações policiais, reuniões de líderes políticos e chefes militares, atuação de jornalistas e da imprensa que procuravam combater o narcotráfico e a onda de violência que ele propagou.

É por isso que alguns personagens - sobretudo os políticos executados por Escobar - são apresentados sob uma ótica muito favorável, em franca contraposição ao narcotraficante. Com o desenrolar dos fatos, conhecemos diversas figuras que se dedicaram à luta contra o tráfico e o terror orquestrados por Pablo Escobar. Entre eles está Luis Carlos Galán Sarmiento (figura "heroica" que será alvo de nossa análise), advogado, economista, jornalista e político colombiano, pré-candidato à presidência da Colômbia pelo Novo

5 Disponível em:<http://elpais.com/elpais/2013/o8/22/opinion/1377179779_669163.html>. Acesso em: 07 out. 2015. 
Liberalismo. Galán prometeu lutar contra o narcotráfico e o crime organizado no país, tendo a extradição dos criminosos para os Estados Unidos sua principal arma. Tal fato suscitou diversas ameaças por parte do narcotraficante. Galán foi assassinado durante um comício na praça principal do município de Soacha, em plena campanha ao cargo de mandatário máximo do país. O candidato morreu, em 1989, crivado de balas enquanto discursava em cima do palanque. Tal acontecimento transformou-se em um dos signos do narcoterrorismo, de 1984 a 1993, na Colômbia.

\section{Da figuração de herói e anti-herói}

A concepção de estilo televisivo e o percurso metodológico apresentado por Jeremy Butler (2010) guiam a análise aqui empreendida. Em verdade, essa proposta tem orientado muitas das análises sobre produtos televisuais já realizadas (ROCHA, 2013, 2014, 2015). Butler conceitua o estilo como qualquer padrão técnico de som-imagem que sirva a uma função dentro do texto televisivo. Tal definição importa tanto por rejeitar concepções que consideram estilo como a marca da genialidade individual em um texto ou como um floreio decorativo de camadas acima da narrativa (embora alguns estilos sejam decorativos) quanto porque, a partir daí, é possível concluir que todos os textos televisivos contêm estilo. Tomando por base noções apresentadas por David Bordwell (2008), Butler afirma que "estilo é a sua estrutura, a sua superfície, a rede que mantém juntos seus significantes e através do qual os seus significados são comunicados" (BUTLER, 2010, p. 15, tradução nossa).

Em seu empreendimento analítico, Butler apresenta quatro dimensões de análise: 1) a descritiva, que abre o texto à análise e tem na semiótica o conjunto mais abrangente de ferramentas para se realizar tal tarefa; 2) a analítica, baseada nos estudos da "teoria funcional do estilo" no cinema de Noell Carrol e que visa detectar os propósitos do estilo e suas funções no texto; 3) a avaliativa, que comunga com a estética a importância de se avaliar a forma final de um produto; 4) a histórica, que requer um recuo histórico para identificar padrões no estilo de um programa ou gênero, por exemplo. Nosso foco será na associação da descrição e da análise para que desvendemos os propósitos 
instituídos por meio de elementos técnicos - figurino, cenário, fotografia, enquadramento, trilha sonora etc na figuração dos significados pretendidos.

\section{A construção herói/anti-herói}

O estilo pode ajudar-nos a entender construções e representações dos personagens na narcotelenovela. As sequências que serão analisadas estão no episódio 8 da versão brasileira e correspondem à campanha política dos personagens. Galán faz seu discurso entre 13:33 e 15:05. Após descobrir que Pablo Escobar é um traficante de drogas, decide manter distância, e foca seu texto na preocupação com a Colômbia e seu povo. Já o discurso de Pablo Escobar acontece aos 16:00 até 17:45 e agradece o carinho do povo e reafirma o apoio à candidatura de Galán, a quem pede um "Viva!" durante sua fala.

A cena do discurso de Galán começa, na verdade, com uma série de planos que o acompanham enquanto o político se aproxima do palanque montado na principal praça do país, onde estão localizados o palácio presidencial (Palácio Nariño) e o edifício do congresso nacional. O dia está claro. É neste cenário que Galán, emoldurado e engradecido por símbolos e monumentos nacionais importantes (Figs. 1 e 6), dirige-se ao povo,. Nesses planos, vários elementos cenográficos entram em cena para demonstrar o apoio da população ao candidato. A cor de sua gravata é ecoada nas roupas, cartazes e bandeiras de todos os figurantes, o que cria uma unidade visual que aponta para a proximidade entre ele e o povo (Fig.2).

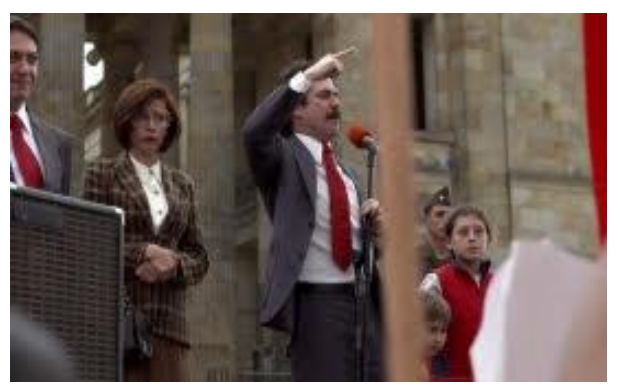

Figura 1: Galán em contra-plongée na praça principal da capital colombiana. 


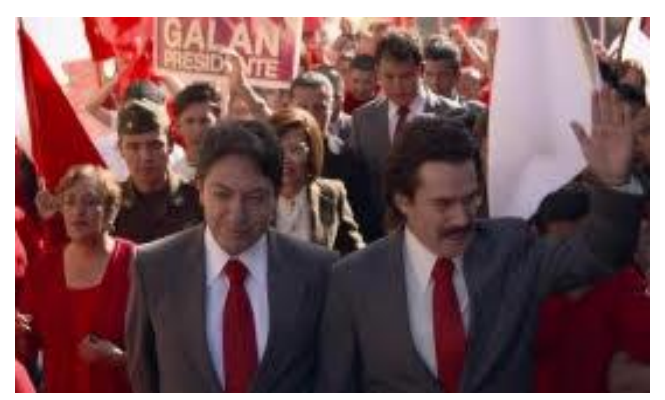

Figura 2: Proximidade entre candidato e povo figurada por uma unidade visual.

Em meio a este ambiente, no qual foi criada uma unidade através das escolhas de figurino e cenário, Galán sobe ao palanque e é isolado pelo enquadramento em contra-plongée, que o engrandece ao mesmo tempo em que coloca o espectador na posição análoga à dos presentes no comício (Fig. 1). No mesmo enquadramento, na parte central superior, vemos a bandeira da Colômbia, alinhada, por instantes, com a cabeça de Galán (Fig. 3). A câmera logo recua e enquadra Galán em um contra-plongée suave, contornado pelas bandeiras erguidas pelo público presente, o que ressalta novamente a contiguidade e o apoio ao candidato. O público é mostrado então em plongée com a cor vermelha em evidência, novamente emprestando unidade. A abertura da tomada eleva a força numérica dos eleitores de Galán (Fig. 4).

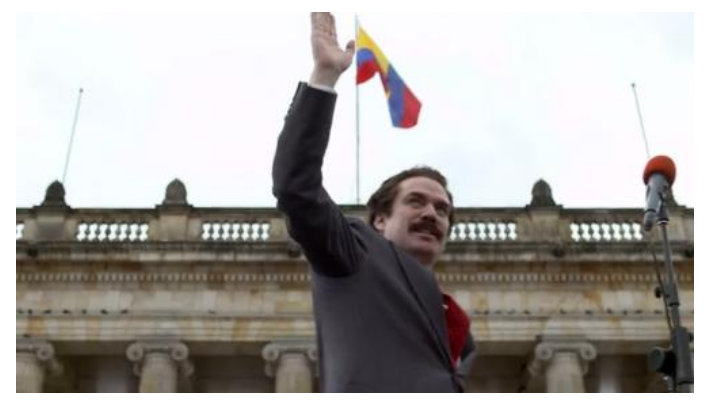

Figura 3: Galán e a bandeira nacional alinhados.

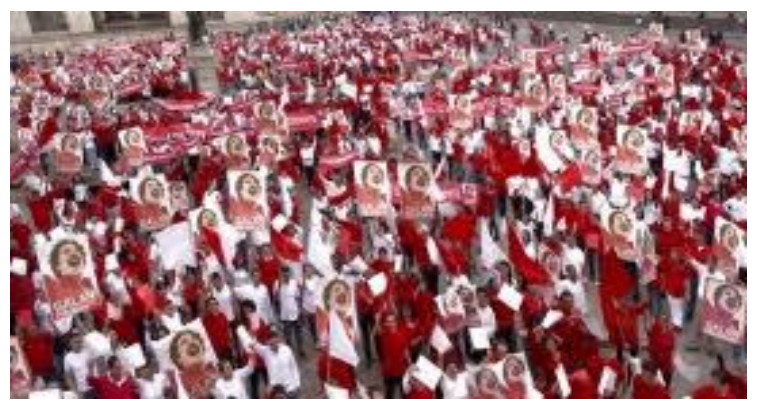

Figura 4: Tomada do público em plongée. 
Retornamos momentaneamente ao contra-plongée, dessa vez com Galán fora do centro, acompanhado por sua esposa e seu braço direito com o palácio ao fundo. $\mathrm{O}$ enquadramento realiza um leve afastamento, mostrando o trio de protagonistas da cena emoldurados por cartazes e pelas mãos dos eleitores. $\mathrm{O}$ microfone de Galán também reforça o vermelho partidário, e na parte traseira de uma faixa erguida na tela, lemos "nuevo liberalismo" (nome da vertente política do candidato) também em vermelho. Segue-se uma sequência de imagens do público presente, com a trilha sonora ocupada por gritos do nome Galán e uma faixa musical instrumental. O primeiro plano dessa sequência mostra o público em um enquadramento na altura do olho humano, com as bandeiras ocupando a parte superior do quadro. Mais dois enquadramentos do público em plongée, um lateral e um frontal, nos quais o candidato aparece de costas para a câmera (Fig.5) que reforça, uma vez mais, a contiguidade com o povo, antecedem o momento em que a câmera retorna ao rosto de Galán, para um primeiro plano em que marca o início de seu discurso (Fig. 6).

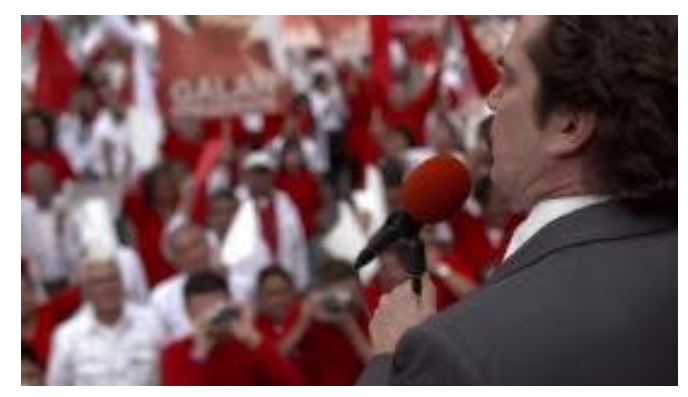

Figura 5: Contiguidade entre Galán e povo.

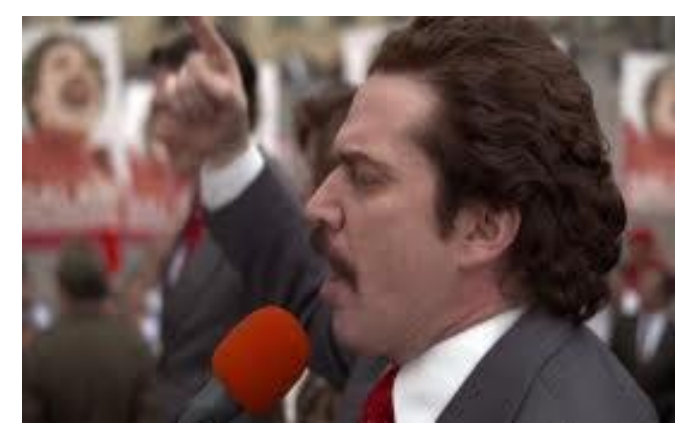

Figura 6: Primeiro plano de Galán.

Nestas sequências chama a atenção a direção de atores, pois a personagem demonstra ser combativa, corajosa, disposta a lutar por Colômbia e seu povo numa guerra contra o narcotráfico. Tal fato é evidenciando por um gestual firme e vigoroso, punho cerrado, dedo em riste. $\mathrm{O}$ enquadramento 
mantém seu ângulo, mas desliza de maneira curva para o centro em um pequeno travelling, dando destaque a Galán (Fig.6). Nesse sentido, retomamos o argumento de que os realizadores televisivos preocuparam-se em recriar imagens realistas do esforço do Estado e seus agentes (Galán era senador) em subjugar a máfia naqueles anos.

O público e suas bandeiras vermelhas em contraste com o céu nublado retornam ao quadro. Um enquadramento em plano médio a partir do ponto de vista do público, em direção ao palanque, retorna pela terceira vez e se desfaz quando a câmera enquadra o candidato discursando em um plano ainda mais aberto que, em uma divisão tripartida clássica da imagem fotográfica faz-nos perceber que Galán está no eixo direito, posicionado em frente a um monumento histórico grandioso, como se este emprestasse ao político suas características de maneira simbólica, e o mar de bandeiras vermelhas ocupando o primeiro terço (lado esquerdo) da imagem. O ponto de fuga da profundidade de campo direciona a visão diretamente para Galán. A câmera movimenta-se em um sutil travelling e se aproxima de Galán na diagonal. O plano que mostra o público retorna, um plongée feito sobre o ombro esquerdo de Galán, e, mais uma vez, reforça a posição de poder de Galán em relação à multidão. Novamente o senso de coletividade sugerida pela unidade visual nas cores vermelha, cinza e branca ressurge, tomam inteiramente a tela e ligam Galán aos eleitores (Fig.5).

No contraplongée seguinte, com Galán ao centro, o candidato é flanqueado por sua família, e sua mulher e filhos aparecem também engrandecidos pelo ângulo de filmagem. Quando a cena se encaminha para o fim, os filhos de Galán ganham mais destaque perante a câmera, sendo filmados em um plano americano levemente alterado (com ângulo um pouco indireto). A câmera, que se move em direção às crianças, que também vestem o vermelho que alinhava a cena, encontra obstáculos na proximidade das bandeiras do público. Essa colisão possível da câmera com as bandeiras reforça a proximidade do público em relação a Galán e sua subsequente fragilidade, como um presságio para o seu futuro assassinato (Figs. 7 e 8). 


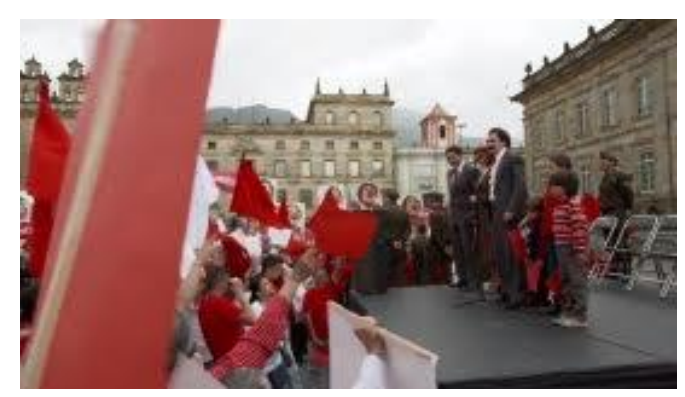

Figura 7: Galán e família.

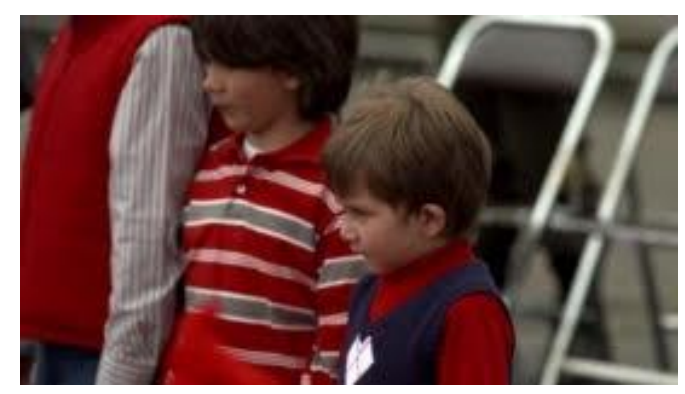

Figura 8: Galán e família.

Assim como na tradição estética do romance popular, na narcotelenovela também temos o elemento de decisão, a entrada do herói, cuja função primordial é a de resolver a situação-problema colocada. É nesse sentido que notamos uma significativa importância, no eixo dramático, de personagens virtuosos que lutam contra o Cartel de Medellín e são apresentados como os verdadeiros heróis da história, como foi o caso de Luis Carlos Galán. Por trás de muitas sequências e diálogos, escondem-se discursos e representações do mundo que o imaginam polarizado, dividido de maneira maniqueísta entre os bons e os maus, o que infringem a lei e os que os combatem. Nesse sentido, é importante ressaltar que a solução da situação-problema, qual seja, vencer a guerra contra as drogas, na narcotelenovela, resulta fantástica no sentido político: na narrativa seriada tal guerra termina com a morte de Pablo Escobar levada a cabo pelo "bloco de busca”, liderado pelo presidente César Gaviria.

Logo após a sequência do discurso de Galán, uma tomada aérea da cidade de Medellín introduz a sequência que trará o discurso de Pablo. Enquanto o primeiro fala em um cenário que diz muito acerca dos significados pretendidos pela perspectiva adotada na narcotelenovela, já que Galán discursa em frente ao palácio presidencial, na principal praça pública de Bogotá, Escobar discursa em 
um local indefinido, sem qualquer simbolismo forte ou evidente, já ao anoitecer. No enquadramento predominam planos fechados e conjuntos.

O trabalho de direção de fotografia intensifica a fragmentação que ocorre entre essas duas sequências - se no discurso de Galán as cores quentes são ressaltadas pela imagem, o cinza ganha destaque no tratamento de imagem quando o núcleo de Escobar entra em cena. Antes do discurso, jovens colam cartazes e estendem faixas da campanha de Pablo em um bairro popular de Medellín. O som não diegético invade essas imagens acompanhado de uma trilha musical mais tensa e dissonante.

A sequência é iniciada a partir do ponto de vista do público, com uma câmera que avança lentamente em direção ao candidato Ortiz (Fig. 8). Logo a cena é enquadrada por trás dos ombros do Pablo, o que torna sua figura grande, embora indefinida, de frente para o público, que é visto em plongée. Nesta cena, o público é filmado praticamente da mesma maneira pela qual as cenas do povo foram filmadas na sequência de Galán, mas com profundidade de campo reduzida, sugerindo ao espectador que o número de presentes no comício de Ortiz e Pablo era menor (Fig. 9). Em seguida, uma das tomadas chave dessa sequência: em um plano conjunto quatro homens se posicionam alinhados em frente a quatro bandeiras verdes (cor ausente da bandeira da Colômbia), Ortiz à frente. Ao contrário do que acontece na cena de Galán, o figurino dos homens (Pablo Escobar incluso) não ecoa as cores da bandeira do país ou do partido, o que aponta para uma dissonância entre os interesses dos homens no palanque com os ideais do povo. Estes homens não olham diretamente para o público de eleitores, ao contrário, se entreolham e trocam sorriso, sugerindo uma falta de contiguidade, tão presente durante o discurso de Galán (Fig. 10).

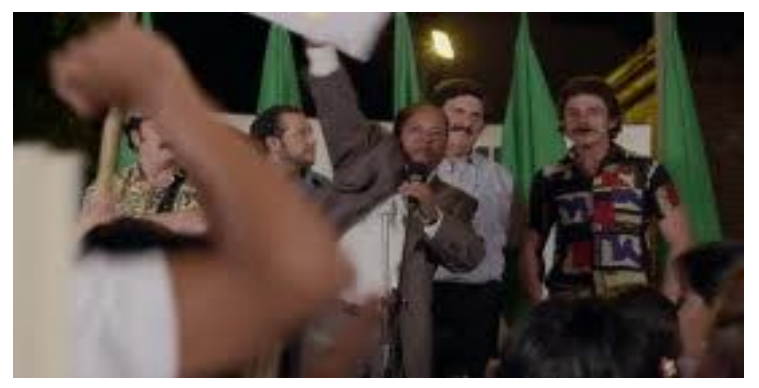

Figura 8: Ortiz. 


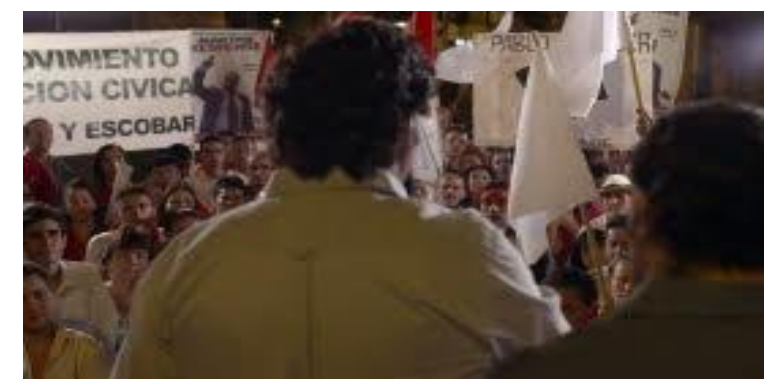

Figura 9: Pablo Escobar.

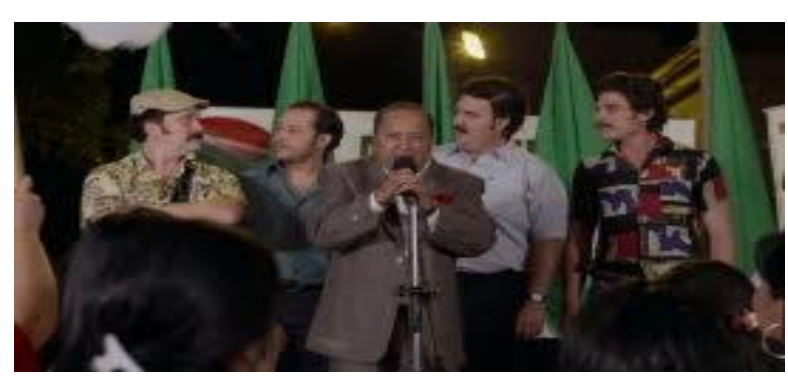

Figura 10: Os homens no palanque se entreolham.

Ortiz apresenta Pablo para o público (que brada pelo narcotraficante na banda sonora) e o protagonista é filmado em um contra-plongée muito suave, quase sem angulação, sem o engrandecimento que a câmera emprestou a Galán, e sua linguagem corporal é hesitante. Pablo ajusta o microfone e mantém um braço escondido atrás de suas costas (Fig.11) em contraste com a linguagem corporal expansiva e decidida de Galán. A câmera assume então uma posição em plongée, revelando as costas dos homens no palanque de frente para o público. Destaque para a direção de atores, já que o telespectador assiste a um grupo desengajado, sem entusiasmo e sem unidade visual no que tange ao figurino dos eleitores de Pablo localizados na linha de frente do (Fig. 12). Mais uma vez o enquadramento escolhe as costas de Escobar, com o público em segundo plano, desta vez, em uma tomada mais fechada e centralizada. Quando, após uma repetição de alguns dos enquadramentos já descritos, a câmera retoma a posição que revela cinco bandeiras verdes e o discursante centralizado, a equipe de Escobar continua movimentando-se, trocando olhares e sorrisos no segundo plano. Quando a banda sonora retoma os gritos de "Pablo", o primo do narcotraficante acena para interromper os eleitores e pedir silêncio, aumentando a distância subjetiva entre aqueles no palanque e aqueles que os assistem. 


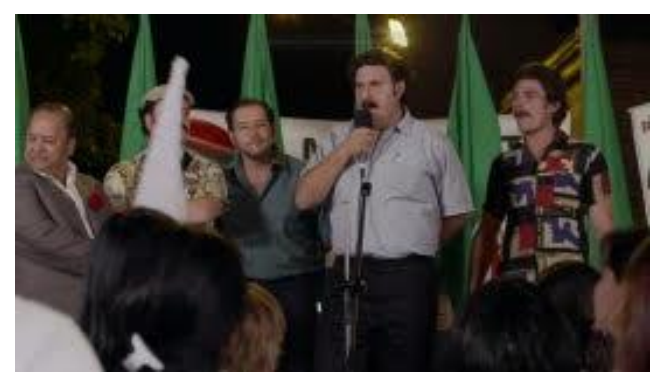

Figura 11: Os homens de Pablo alinhados à frente de bandeiras verdes.

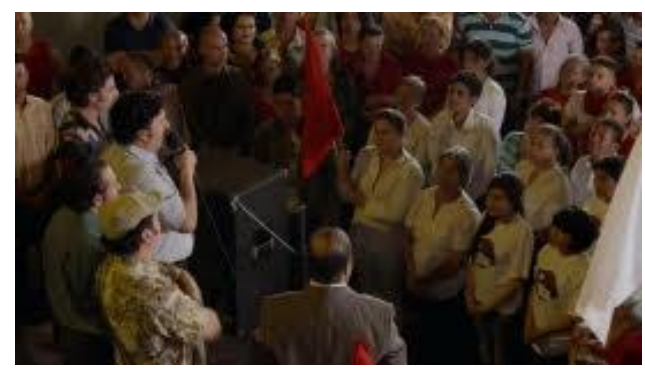

Figura 12: A falta de entusiasmo do público.

Durante todo o discurso, a câmera passa a operar em uma alternância entre dois planos em contra-plongée suave. A mão esquerda de Escobar permanece escondida atrás de suas costas até o momento em que, ao pedir vivas para Galán, ergue a sua mão emulando a linguagem corporal do outro candidato - uma espécie de mise-en-scene do personagem que toma para si uma linguagem que não é sua, um artifício. A sequência termina com um plano que revela uma maleta de dinheiro aberta e a distribuição subsequente do mesmo para o público presente.

Escobar não usurpou o lugar do herói. As escolhas estilísticas deixaram claro a quem se quis posicionar como tal. Já o capo, na verdade, foi o anti-herói; pois herói eram seus opositores. Os realizadores estrategicamente posicionaram Escobar numa função estrutural de ser a principal força que promove com suas ações uma realidade cotidiana sumamente problemática: a de Medellín e seu narcotráfico. Mas ele, de alguma forma, era querido e amado pelo povo humilde de sua região. Distribuía dinheiro, patrocinava obras de caridade, doava casas e remédios aos pobres ${ }^{6}$. Nesse sentido, não pareceu mera casualidade que, em um

${ }^{6}$ Em Medellín, por exemplo, existe um bairro construído, em 1984, pelo narcotraficante e que recebeu seu nome, "Bairro Pablo Escobar". Em 2010, habitavam nele cerca de três mil famílias, muitas das quais mantinham em suas casas estatuetas de gesso que representavam o capo com figurino de Robin Hood. Cf. Diario Hoy publicado em o2 de 
dos episódios a jornalista Regina (Virginia Vallejo) apareceu explicando a Escobar, na piscina de uma mansão, porque a imprensa escrita o comparou com a lenda e o apelidou de "Robin Hood de Medellín”:

Como creó millares de empleos -lícitos e ilícitos-, era pródigo y derrochador y encarnó la idea de que uno podía hacerse rico de la noche a la mañana pegando tiros, fue un ídolo en los barrios marginales de Medellín y por eso, a su muerte, millares de pobres lo lloraron, llamándolo un santo y un segundo Jesus Cristo.7

Os elementos estilísticos que se sobressaíram na figuração dos personagens na narrativa seriada foram o enquadramento, o cenário, a atuação dos atores dentro do quadro e os elementos cenográficos. Ou seja, a configuração de um ponto de vista e de uma ambiência propícia à representação construída para cada um segundo uma finalidade expressiva. Em termos de enquadramento, Galán quase não aparece no centro da tela nem em contraplongée extremo como Pablo. A câmera sempre coloca em evidência sua interação com o público. Seu comício foi realizado em dia claro, na principal praça pública da capital, com símbolos e edifícios importantes e o candidato cercado pela família, o que contribui para figurá-lo como um cidadão de bem, virtuoso e íntegro. Já Escobar nos é apresentado sempre em contra-plongée extremo, ressaltando sua (im)postura de um homem acima do bem e do mal. Num comício realizado à noite, em um local não identificado, o narcotraficante está cercado por seus capangas, tem pouca interação com o público e um gestual contido.

\section{Considerações finais}

Partindo de uma análise estilística da produção colombiana Escobar: el patrón del mal, nosso propósito foi o de compreender como uma conjuntura de preferências técnicas contribuíram para configurar o contexto e a problemática bem como os traços de personalidade e caráter das personagens, segundo significados pretendidos pelos realizadores da produção.

maio de 2010.

7 Disponível em: http://elpais.com/elpais/2013/08/22/opinion/1377179779 669163.html. Acesso em: 07 out. 2015. 
As escolhas estilísticas identificadas na textura tangível do produto tornaram evidente a pretensão de contar a historia não apenas sob um enfoque sociodelictivo, mas também segundo um ponto de vista político, no qual heróis nacionais deram sua vida na guerra contra o narcotráfico. Nesse sentido, é possível vislumbrar uma característica que envolve uma espécie de catarse, de consolação, algo como a Colômbia prestando contas a si mesma, ao figurar quem tentasse impedir tamanho estrago na vida social, política e econômica do país. Todavia, a solução para tal conflito acabou sendo da ordem do fantástico, pois, a guerra contra as drogas, na produção televisiva, termina sendo vitoriosa com a captura e morte de Escobar. Embora o narcotraficante tenha morrido em 1992, o fim da guerra não condiz com a realidade histórica. Sendo assim, consideramos que nesse nível "catártico" encontra-se uma das propostas de significado ou mensagem dominante pretendida pelos produtores televisivos junto à audiência.

\section{Referências}

BORDWELL, D. Figuras traçadas na luz: a encenação no cinema. Campinas, Papirus, 2008.

BUTLER, J. Television Style. New York: Routledge, 2010.

ESCOBAR: el patrón del mal: Produção: Juana Uribe e Camilo Cano. Colômbia: (C)Caracol Televisión. 2012. 113 episódios.

LÓPEZ DE LA ROCHE, F. Las ficciones del poder. Patriotismo, medios de comunicación y reorientación afectiva de los colombianos bajo Uribe Vélez(2002-2010), IEPRI-Penguin Random House, Bogotá, 2014.

NEIRA REYES, L. F. E LÓPEZ DE LA ROCHE, F. La serie de televisión "PabloEscobar: El patrón del mal" y las representaciones ficcionales de la cultura del narcotráfico en Colombia. Ponencia presentada al Simpósio 9: "Diálogos possíveis: a cultura nas ciências humanas latino-americanas" de las IV Jornadas Internacionales de Problemas Latinoamericanos "América Latina: luchas, experiencias y debates por una integración de los pueblos", Foz de Iguazú, Brasil, 27 al 29 de noviembre de 2014.

ORDOÑEZ, María Dolores. Las narco telenovelas colombianas y su papel en la construcción discursiva sobre el narcotráfico en América Latina. Tesis de maestría. Universidad Andina Simón Bolívar. Sede Ecuador, 2012.

RINCÓN, O. Todos temos um pouco do tráfico dentro de nós: ensaio sobre narcotráfico/cultura/novela como modo de entrada para a modernidade. MATRIZes, Ano 7 - No 2 jul./dez. 2013 - São Paulo - Brasil, pp. 193-219. 
RINCÓN, O. Narco.estética y narco.cultura en Narco.lombia. Nueva Sociedad \#222, Jul.-Ago, 2009. pp. 147-163.

ROCHA, S. M. Desenvolvimento tecnológico, estilo televisivo e telenovelas: possíveis reconfigurações do gênero na produção de Gabriela. Galáxia (São Paulo. Online), v. 1, p.180-194, 2015.

ROCHA, S. M. O estilo televisivo e sua pertinência para a TV como prática cultural. Revista Famecos. Porto Alegre. v. 21, n. 3, p. 1082-1099. set./dez. 2014..

ROCHA, S. M; ALVES, M. L. C; OLIVEIRA, L. F. de. A História através do estilo televisivo: a Revolta da Vacina na telenovela Lado a Lado. Revista EcoPós (Online), v. 16, 2013. 